DanaraJ, T.J. \& WoNG, H.O. (1959) Primary arteritis of the abdominal aorta in children causing bilateral stenosis of the renal arteries and hypertension. Circulation, 20, 856.

DanaraJ, T.J., Wong, H.O. \& Thomas, M.A. (1963) Primary arteritis of the aorta causing renal artery stenosis and hypertension. British Heart Journal, 25, 153.

Kondo, B., Windsor, T., Raulston, B.O. \& Kuroiwa, D. (1950) Congenital coarctation of the abdominal aorta. A theoretically reversible type of cardiac disease. American Heart Journal, 39, 306.

MAYCOCK, W.D'A. (1937) Congenital stenosis of the abdominal aorta. American Heart Journal, 13, 633.

Milloy, F., \& Fell, E.H. (1959) Elongate coarctation of the aorta. Archives of Surgery, 78, 759.

Sen, P.K., Kinare, S.G., Engineer, S.D. \& Parulkar, G.B (1963) The middle aortic syndrome. British Heart Journal, 25, 610 .

\title{
A case of self-poisoning with Carbrital
}

\author{
JoHN COLLINS \\ B.D.S., M.B., M.R.C.P. \\ Registrar in Clinical Toxicology and Intensive Care, Guy's Hospital, \\ London, S.E.1
}

\section{Case Report}

A 67 year-old woman was admitted one-and-a-half hours after taking 50 capsules of Carbrital, each containing pentobarbitone sodium $100 \mathrm{mg}$ and carbromal $250 \mathrm{mg}$.

On admission she was comatose and areflexic except for the prese:vation of the cough reflex. The pulse was 72 /minute, sinus rhythm and tlood pressure $90 / 50 \mathrm{mmHg}$. There were no signs of cardiac or peripheral circulatory failure at this time.

In the accident and emergency department gastric lavage was performed with a wide-bore tube. An intravenous infusion was set up with $1 / 6$ molar sodium lactate solution and frusemide $20 \mathrm{mg}$ was given intravenously. The patient was then transferred to the Medical Intensive Care Unit for further treatment.

\section{First $24 \mathrm{hr}$}

For the first $24 \mathrm{hr}$ after admission an alkaline diuresis was produced using alternate $540 \mathrm{ml}$ bottles of $1 / 6$ molar sodium lactate solution and $5 \%$ dextrose solution. Potassium chloride $0.75 \mathrm{~g}$. (10 mEq.) was added to alternate bottles and the diuresis was maintained by intermittent intravenous frusemide, $380 \mathrm{mg}$ being administered in $24 \mathrm{hr}$. In addition the patient was given hydrocortisone $100 \mathrm{mg}$ intramuscularly 4-hourly and $35 \%$ oxygen by Ventimask.

A chest X-ray taken during this period showed a vaguely outlined radio-opaque mass in the left hypochondrium. It was suggested that this could possibly be the ingested capsules; subsequent events lent support to this suggestion.

Throughout this period the blood pressure never rose above $95 / 60 \mathrm{mmHg}$ and the rectal temperature was consistently below $94^{\circ} \mathrm{F}$ at one point. The patient remained deeply comatose but the cough reflex was preserved.

\section{Second $24 \mathrm{hr}$}

It was decided to abandon the alkaline diuresis and the intravenous infusion was continued at a slower rate with alternating bottles of normal saline and $5 \%$ dextrose with similar quantities of potassium chloride in alternate bottles.

After $40 \mathrm{hr}$ spontaneous respiration ceased and the patient developed atrial fibrillation. An endotracheal tube was passed and respirations were maintained using an East Radcliffe Positive Pressure Ventilator. Following this the patient reverted to sinus rhythm spontaneously.

$46 \mathrm{hr}$ after admission the patient suffered a cardiac arrest but was restored to sinus rhythm after a brief period of external cardiac massage and one DC countershock of 100 Joules.

\section{After $48 \mathrm{hr}$}

Following this episode of cardiac arrest no further cardiac dysrhythmias were noted and the level of consciousness slowly rose. At $74 \mathrm{hr}$ the endotracheal tube was removed and spontaneous respiration was restored. $90 \mathrm{hr}$ after admission the patient was sufficiently conscious to answer simple questions coherently and was then transferred to a general medical ward. The patient was referred to a Consultant Psychiatrist and was discharged 24 days after admission to receive outpatient treatment for depression.

\section{Findings}

In the first 24-hr $11,200 \mathrm{ml}$ of fluid were administered by intravenous infusion and 11 litres of urine were produced. The $\mathrm{pH}$ of each $500 \mathrm{ml}$ collected was shown to be greater than 8 .

During this period the plasma potassium was consistently low reaching $2 \cdot 3 \mathrm{mEq} / 1$ at one point. The plasma bicarbonate (auto-analyser) was raised 
to $58 \mathrm{mEq} / \mathrm{l}$ and remained elevated for the first $48 \mathrm{hr}$. Throughout this period the range of the plasma $\mathrm{pH}$ was 7.41-7.51 and for the $\mathrm{PaCO}_{2}$, 77-93 $\mathrm{mmHg}$.

At the time of the cardiac arrest $(46 \mathrm{hr})$ the plasma potassium was $2.6 \mathrm{mEq} / 1$ and the plasma levels of pentobarbitone and bromide were $2.75 \mathrm{mg} / 100 \mathrm{ml}$ and $6.7 \mathrm{mg} / 100 \mathrm{ml}$ respectively.

In the second $24-\mathrm{hr} 4070 \mathrm{ml}$ of fluid were administered by intravenous infusion and $2475 \mathrm{ml}$ of urine were collected.

At the time the patient regained consciousness the plasma pentobarbitone level was $0.8 \mathrm{mg} / 100 \mathrm{ml}$.

A total of 17 litres of fluid was administered by intravenous infusion and 16 litres of urine were collected. In 11 litres of the urine $104.4 \mathrm{mg}$ of pentobarbitone were recovered and the total in 17 litres of urine was unlikely to be in excess of $153 \mathrm{mg}$.

Fig. 1 shows the chest X-ray taken on admission and the radio-opaque mass can be seen in the left hypochondrium. This mass was visible on serial $\mathrm{X}$-rays during the first 72-hr after admission but 90 $\mathrm{hr}$ after admission it was no longer visible on X-ray.

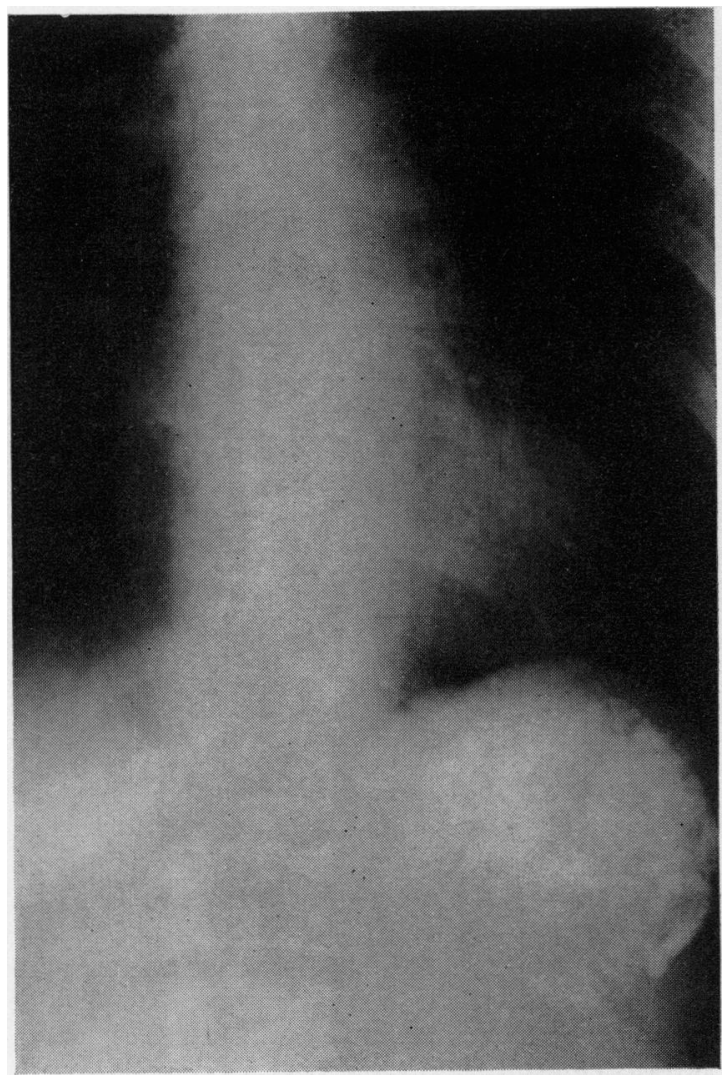

Fig. 1. Chest X-ray on admission showing an opacity in the left hypochondrium.
To test the suggestion that this mass consisted of partially digested Carbrital capsules, a mass of these were incubated with dilute hydrochloric acid at $38^{\circ} \mathrm{C}$ and this mass was then X-rayed. This X-ray is shown in Fig. 2. This supports the suggested explanation of the opacity on the abdominal X-rays.

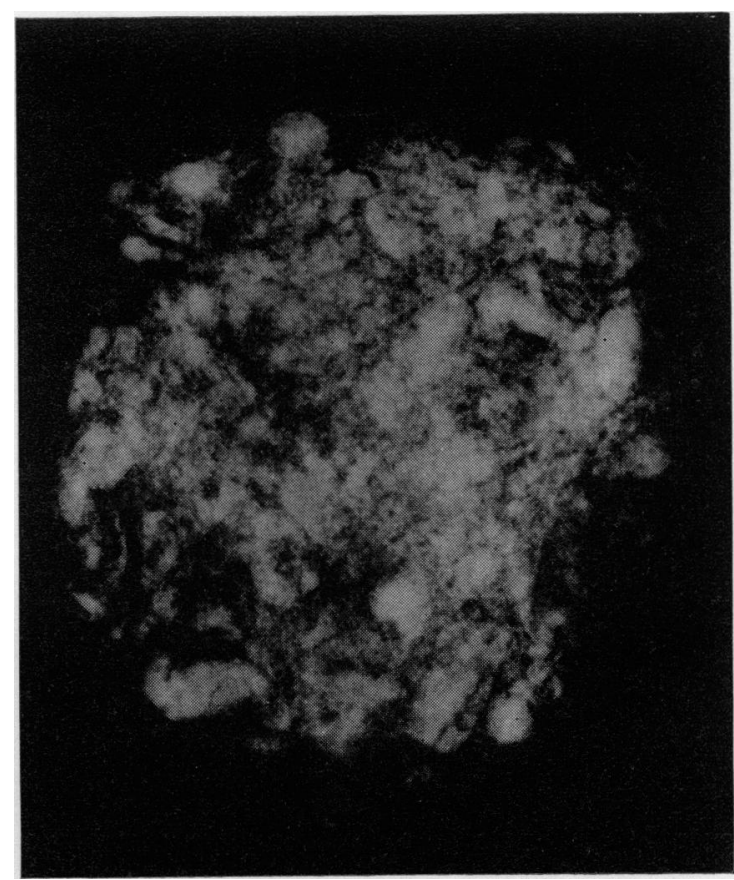

FIG. 2. X-ray of a mass of Carbrital capsules digested with $\mathrm{N} \mathbf{H C l}$ for $2 \mathrm{hr}$.

\section{Discussion}

There are several interesting features about this case. Although gastric lavage using a wide-tore tube was carried out within $2 \mathrm{hr}$ of ingestion of the capsules, it failed to remove the large bulk of them. As a result the patient continued to absorb the drugs over a prolonged period.

With the collection of 11 litres of urine in the first 24-hr there was no doubt that the diuresis was massive and with a urine $\mathrm{pH}$ of 8 it was certainly alkaline, but the quantity of pentobarbitone eliminated by this technique was only $104.4 \mathrm{mg}$, which is equivalent to the content of one Carbrital capsule. In spite of intravenous potassium supplements the technique produced a severe hypokalaemic alkalosis in the presence of respiratory carbon dioxide retention.

The respiratory arrest occurred when the plasma content of each drug, if present alone, was sufficient to produce coma. 


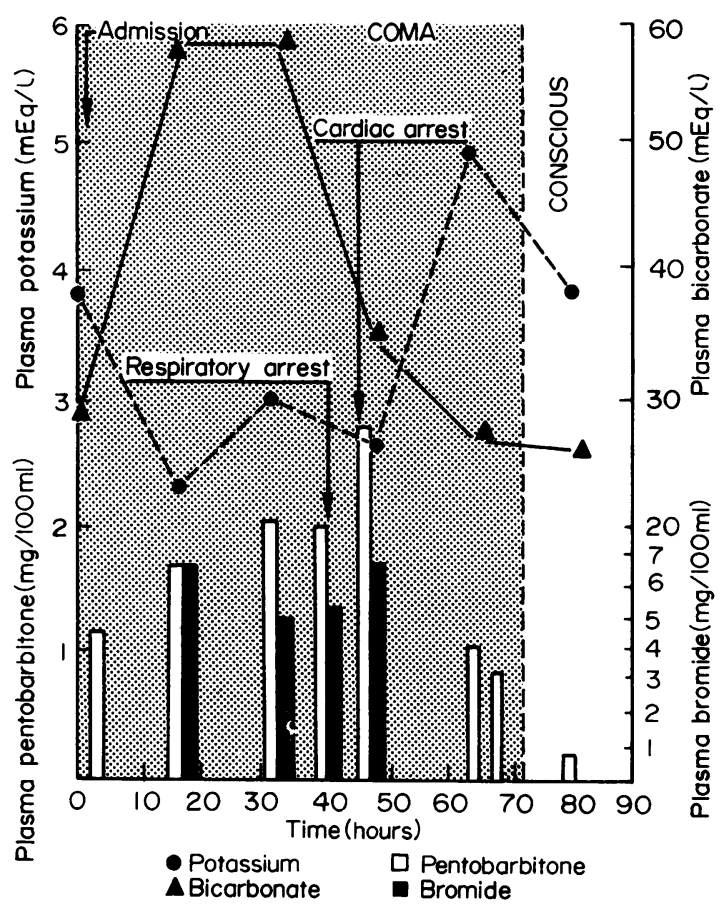

Fig. 3. Graph to show the relationship of serum concentrations of potassium and bicarbonate to serum concentrations of pentobarbitone and bromide.

Factors contributing to the cardiac arrest were even higher levels of both drugs, pentobarbitone
$2.75 \mathrm{mg} / 100 \mathrm{ml}$ plasma, and bromide $6.7 \mathrm{mg} / 100$ $\mathrm{ml}$ plasma; profound hypothermia, rectal temperature $89^{\circ} \mathrm{F}$; and hypokalaemia with a plasma potassium of $2.6 \mathrm{mEq} / \mathrm{l}$.

Mawer \& Lee (1968) have shown that renal excretion of unchanged pentobarbitone using forced alkaline diuresis has no therapeutic significance in the management of poisoning with pentobarbitone. Bloomer (1965) also found forced diuresis to have only limited value in the management of poisoning with this drug.

The results of this case suggest that their views apply equally to poisoning with Carbrital. The yield of pentobarbitione in the urine was insufficient to be helpful in management and dangerous complications may easily be produced by this technique.

It is suggested that the recommendations of Matthew \& Lawson (1966) for a policy of conservative management in the treatment of most cases of poisoning with intermediate-acting barbiturates should be followed in cases of poisoning with Carbrital.

\section{References}

MAwer, G.E. \& LeE, H.A. (1968) Value of forced diuresis in acute barbiturate poisoning. British Medical Journal, 2, 790-793.

BLOOMER, H.A. (1965) Limited usefulness of alkaline diuresis and peritoneal dialysis in pentobartital poisoning. New England Journal of Medicine, 272, 1309-1313.

MatThew, H. \& Lawson, A.A.H. (1966) Acute barbiturate poisoning. A review of two year experience. Quarterly Journal of Medicine, 35, 539-552.

\title{
Clostridium septicum infection of the thyroid gland
}

\author{
C. P. W. WARREN \\ M.B., B.CHIR., M.R.C.P. \\ Senior Medical Registrar
}
B. J. MASON
M.R.C.P.

Medical Registrar

\section{Royal Hampshire County Hospital, Winchester}

A CASE of infection of the thyroid gland by Clostri-
dium septicum is described, which is only the fourth
case of gas-forming suppurative thyroiditis to be
reported and the first in which the causative orga-
nism has been identified.

The case also illustrates a most unusual presentation of carcinoma of the colon.

\section{Case report}

A 58-year-old man who worked as a cold store attendant was admitted to hospital with a painful inflamed swelling of his neck. The swelling was in the region of the thyroid gland and had developed in $12 \mathrm{hr}$ with dysphagia and positional stridor. Rigors had occurred at the onset of the illness. His thyroid gland had been enlarged for 20 years and a firm enlargement of the right lobe had been noted on admission to hospital 2 years earlier. The patient looked ill and pale, and had a temperature of $103^{\circ} \mathrm{F}$. He was clinically euthyroid. His neck was swollen, inflamed and tender due to enlargement of the thyroid gland, particularly on the right side. There 